\title{
Plasma neuropeptide-Y levels, monoamine metabolism, electrolyte excretion and drinking behavior in children with attention-deficit hyperactivity disorder
}

\author{
Robert D. Oades ${ }^{1}$, R. Daniels ${ }^{2}$, W. Rascher ${ }^{3}$ \\ ${ }^{1}$ Clinic for Child and Adolescent Psychiatry, University of Essen, Virchowstr. 174, 45147 Essen, \\ Germany \\ ${ }^{2}$ Department of Internal Medicine, German Cancer Centre Essen, Essen, Germany \\ ${ }^{3}$ Department of Pediatric Nephrology, University of Essen Medical School, Virchowstr. 175, 45147 \\ Essen, Germany
}

1998 Psychiatry Research 80, 177-186

\begin{abstract}
Against a background of (a) increased drinking behavior in children with attention-deficit hyperactivity disorder (ADHD); (b) the parallel between some behaviors associated with ADHD and hypertension; (c) the use of the spontaneously hypertensive rat as a model for ADHD; and (d) similarities in the changes of neuropeptide Y (NPY) and catecholamine in studies of hypertension and drinking, NPY, catecholamines and electrolyte balance were compared in the plasma and urine of healthy children and those with ADHD.

Drinking was monitored during $3 \mathrm{~h}$ of neuropsychological tests over 2 days in 14 ADHD and nine healthy children. Patients drank four times as much water and showed twice the levels of NPY found in controls. In controls there were positive and in patients there were negative relationships for NPY with drinking and restless behavior. Patients' plasma levels of norepinephrine (NE) and epinephrine were slightly elevated, but urinary levels of NE and the serotonin metabolite were markedly increased. Urinary excretion rates for sodium (not potassium), phosphate and especially calcium were decreased in patients even after covarying for less urine production in the ADHD group. NPY levels were inversely related to calcium excretion and drinking was inversely related to circulating sodium.

Increases of drinking and circulating NPY in ADHD children and decreased electrolyte excretion may reflect a common disturbance in metabolic homeostasis.
\end{abstract}

Keywords: Attention-deficit hyperactivity disorder; NPY; Thirst; Norepinephrine; Dopamine; Sodium; Calcium; Phosphate

\section{Introduction}

In 1987, in the context of a workshop on attention-deficit disorder in children (Sagvolden and Archer, 1989), RDO was asked about the basis of the widely remarked but scarcely documented increased drinking behavior of this group of children (I. Colquhoun, personal communication). The lack of study of this phenomenon is one reason why we decided to monitor the thirst of a group of children with attention-deficit hyperactivity disorder (ADHD) during a neuropsychological study and explore some potential physiological correlates.
With regard to the potential biological concomitants of this behavior, it had already been suggested (Oades, 1987) that there may be aspects of the interactions between angiotensin II (AII) and norepinephrine (NE) that are relevant to ADHD symptoms. Animal studies have shown that mutual inter-actions between All and NE are integral to the control of thirst, drinking and cardiovascular regulation (Fontes et al., 1994; Xu and Herbert, 1994; Fregly and Rowland, 1995). All and neuropeptide $Y$ (NPY) interact in medullary nuclei including the noradrenergic Nucleus Tractus Solitarius (Aguirre et al., 1992). NPY activity has also been implicated in 
cardiovascular regulation, the increase of drinking and enhanced sodium excretion (Dumont et al., 1992). As it would be difficult to record meaningful indices of central All activity from peripheral measures, but NPY, which is frequently collocated with NE in noradrenergic neurons (Dumont et al., 1992), can be assayed as a marker for neuroblastoma (Rascher et al., 1993), we decided to look at indices of NPY and catecholamine activity in the drinking behavior of ADHD and healthy children.

Two aspects of the function/dys-function of NE and NPY add to the interest in their measurement in ADHD children. First, abnormal activity of NE and NPY contributes to the characteristics of the spontaneously hypertensive rat (Sato et al., 1995) that itself is studied as a putative animal model for ADHD (Oades, 1989; Sagvolden et al., 1993). Children with hypertension may show $50 \%$ increases of $\mathrm{NPY}$, and children of parents with essential hypertension can show changed platelet alpha-2 binding and increased sodium retention even with normal blood pressure (Lettgren et al., 1992). Second, hypertensive adult humans, where increased NPY may mark increased sympathetic nervous activity (Erlinge et al., 1992), show some behavioral features that are reminiscent of the ADHD syndrome [e.g. increased restlessness when medication is withheld (Rascher, personal communication)]; furthermore, increased locomotor activity in hypertensive adults is associated with increases of NPY production (Pruszczyk and Chlebus, 1995) and these subjects may also be slightly impaired on verbal learning and memory (Schmidt et al., 1991).

Finally, we decided to monitor electrolyte excretion that can reflect mechanisms operating in the control of thirst and blood pressure. [In extreme cases, urinary measures of electrolytes and creatinine reflect changes associated with blood pressure regulation (Guyton et al., 1981)]. These were compared with clinically routine measures taken from blood samples from the patients.

\section{Methods}

\subsection{Subjects and procedure}

From the original sample of 16 children with a primary diagnosis of ADHD (DSM-III-R and ICD9) and 16 age-matched healthy controls, there were 14 patients who were given the revised ICD-10 diagnosis F90.x (AD) and 9 healthy control subjects (CN) that also provided blood and urine samples for analysis. The $A D$ group were all inpatients and naive to medication. Subject characteristics and problem ratings on the Conners short parent-teacher scale (CPTQ), here rated by parent and nurse are shown in Table 1. Mean Tanner ratings of secondary sexual development for all subjects was 2.0 or less. Cases with secondary diagnoses that were comorbid with the primary diagnosis of ADHD included conduct disorder (F91.X, $n=4$., social and emotional disturbance (F92.x, $n=4$ ), enuresis-encopresis (F98.x, $n=1$ ), speech (F80.x, ns=1) or motor developmental disorder (F82. $x, n=2)$.

This report considers group differences and correlations first for plasma measures and drinking, second for urinary electrolytes, third for urinary mono-amines and lastly considers the differences recorded in a small group of five patients given low doses of psychostimulant medication for 2-8 weeks (10-30 mg/day methylphenidate, median 20 $\mathrm{mg} /$ day).

\subsection{Procedure}

A battery of neuropsychological tests were presented on 2 separate days with a 24-h urine sample collected on the day between tests (e.g. Oades et al., 1996a, b; Oades and Müller, 1997); this battery usually included the measurement of event-related potentials where the presence of movement artifact $(>65 \mu \mathrm{V})$ was taken as an additional measure of restlessness [Table 1; Oades et al., 1996b; $n=3210$ y-old children (normal, Tourette and AD subjects), mean artifacts $45 \pm 19$, Conners $1.5 \pm 0.7, r=0.5, P=0.01]$.

There was a pause after each test when it was suggested that the subject could turn away from the computer to rest the eyes and have a drink of water while the experimenter prepared the next test. Test sessions together lasted on average for $3 \mathrm{~h}(182.5 \pm 83.8 \mathrm{~min}$; range, 45-343 $\mathrm{min}$ ). A previously measured volume of water was presented in a normal 
drinking glass and the volume controlled at the end of the session. Fluid intake was not controlled in the period immediately prior to

Table 1

Subject characteristics (mean and S.D.)

\begin{tabular}{|c|c|c|c|c|c|c|c|c|c|c|}
\hline Group & & $\begin{array}{l}\text { Gender } \\
(\% \text { male })\end{array}$ & $\begin{array}{l}\text { Age } \\
\text { (years) }\end{array}$ & $\begin{array}{l}\text { Weight } \\
(\mathrm{kg})\end{array}$ & $\begin{array}{l}\begin{array}{l}\text { Education } \\
\text { (years) }\end{array} \\
\text { year }\end{array}$ & $\begin{array}{l}\text { SPM } \\
\text { IQ }^{\mathrm{a}}\end{array}$ & $\begin{array}{r}\text { CPTQ } \\
\text { (mean) }\end{array}$ & $\begin{array}{l}\text { Items/ } \\
10\end{array}$ & Restless & $\mathrm{GFT}^{\mathrm{c}}$ \\
\hline $\mathrm{CN}$ & 9 & 56 & $\begin{array}{l}10.6 \\
\text { Range, } 8.9-12.1\end{array}$ & $\begin{array}{l}40 \\
\pm 6\end{array}$ & $\begin{array}{l}4.5 \\
\pm 1.0\end{array}$ & $\begin{array}{l}114 \\
\pm 10.7\end{array}$ & $\begin{array}{l}0.67 \\
\pm 0.28\end{array}$ & $\begin{array}{l}7.2 \\
\pm 1.9\end{array}$ & $\begin{array}{l}29.1 \\
\pm 16.4\end{array}$ & $\begin{array}{l}43.1 \\
\pm 5.2\end{array}$ \\
\hline $\mathrm{AD}$ & 14 & & $\begin{array}{l}9.8 \\
\text { Range, } 6.5-14.3\end{array}$ & $\begin{array}{l}37 \\
\pm 11\end{array}$ & $\begin{array}{l}3.2 \\
\pm 2.4\end{array}$ & $\begin{array}{l}96^{*} \\
\pm 15.2\end{array}$ & $\begin{array}{l}1.83^{*} \\
\pm 0.76\end{array}$ & $\begin{array}{l}9.4^{*} \\
\pm 1.0 \\
\end{array}$ & $\begin{array}{l}53.2^{*} \\
\pm 13.7\end{array}$ & $\begin{array}{l}56.8^{*} \\
\pm 13.1\end{array}$ \\
\hline
\end{tabular}

Note. There are no significant differences for gender, age, weight and education.

${ }^{a}$ Raven's Standard Progressive Matrices performance (non-verbal IQ).

${ }^{\mathrm{b}}$ Percent movement-contaminated trials removed as artifact in event-related potential records.

${ }^{\mathrm{c}}$ Göttinger complex figure-copying task. $* 0.008>P>0.001$ (two-tailed $t$-test).

Table 2

Mean ( \pm S.D.) plasma levels of epinephrine (Epi), norepinephrine (NE), NPY and water consumption in patients with attention deficit disorder $(\mathrm{AD})$ and controls $(\mathrm{CN})$.

\begin{tabular}{|c|c|c|c|c|c|c|c|c|c|}
\hline Group & $\begin{array}{l}\text { Epi } \\
(\mathrm{pg} / \mathrm{ml})\end{array}$ & $\begin{array}{l}\mathrm{NE} \\
(\mathrm{pg} / \mathrm{ml})\end{array}$ & $\begin{array}{l}\text { NPY } \\
(\mathrm{fmol} / \mathrm{ml})\end{array}$ & $\begin{array}{l}\text { Drinking } \\
\text { rate }(\mathrm{ml} / \mathrm{min})\end{array}$ & $\begin{array}{l}\mathrm{Na}^{+} \\
(\mathrm{mM} / \mathrm{l})\end{array}$ & $\mathrm{K}^{+}$ & $\mathrm{Ca}^{2+}$ & $\mathrm{Cl}^{-}$ & $\begin{array}{l}\text { Creatinine } \\
(\mathrm{mg} / \mathrm{l})\end{array}$ \\
\hline $\mathrm{CN}$ & 81.7 & 481.9 & 2.71 & 0.5 & - & - & - & - & - \\
\hline S.D. & 86.4 & 246.6 & 0.79 & 0.6 & & & & & \\
\hline $\mathrm{AD}$ & 111.9 & 735.5 & $4.15^{*}$ & $2.3^{* *}$ & 138 & 4.4 & 2.4 & 104 & 7.3 \\
\hline S.D. & 86.4 & 446.7 & 1.81 & 2.1 & 3 & 0.3 & 0.1 & 4.7 & 1.0 \\
\hline
\end{tabular}

Note. Plasma electrolytes in patients did not correlate with NPY or catecholamines, but decreases of sodium (only) were weakly associated with increased drinking $(r=-0.54, P<0.055)$.

$* F_{1,18}=5.4, P=0.03 ; * * F_{1,18}=4.54, P=0.047$.

with breakfast over $1 \mathrm{~h}$ before. The duration of the test session was recorded to the nearest minute. Testing followed the approval of the protocol by the clinic management, the agreement of the clinic staff in each individual case and the cooperation, understanding and consent of the child and legally responsible adult.

\subsection{Biochemical measures}

Blood samples, obtained between $08.00 \mathrm{~h}$ and $09.00 \mathrm{~h}$ in the morning in 10-ml EDTAprepared monovettes, were taken on ice to the laboratory for preparation and analysis (details in Rascher et al., 1993). Briefly, the sample was diluted with $1 \%$ trifluoroacetate solution and extracted with pre-washed octadecasilicyl cartridges using a methanoltriethyl-amine buffer at $\mathrm{pH} 4$ (Sep-Pak,
Millipore). The eluate was dried in a vacuum centrifuge and redissolved in phosphate buffer for assay. Synthetic porcine NPY (Bachem Biochemica) coupled to bovine thyroglobulin was used for immunization. (Complete cross-reactivity with human NPY has been established). The anti-serum was incubated for $48 \mathrm{~h}$ prior to a further $48 \mathrm{~h}$ with ${ }^{125}$ I-NPY (Amersham). Antibody-bound and free labeled NPY were separated after adding albumin over dextran coated charcoal. The sensitivity was $3 \mathrm{fmol} /$ tube $(-1.4 \mathrm{fmol} / \mathrm{ml})$, the intra-assay coefficient of variance was $<7 \%$, and the coefficient of variance between assays was c. $15 \%$. Based on 35 young adults and children aged down to 0.1 years, normal mean levels of NPY varied from 1.8-2.4 fmol $/ \mathrm{ml}$. Abnormal levels of NPY were reported with these methods in children with 
neuroblastoma [median $15.2 \mathrm{pmol} / \mathrm{l}$ (Rascher et al., 1993)] and in children and adults with chronic renal failure [5.3-5.9 pmol// (Bald et al., 1997)].

The urine sample collection has been described elsewhere (Oades et al., 1994, 1996a). Briefly, dopamine (DA), norepinephrine (NE), serotonin (5-HT) and their metabolites (homovanillic acid, HVA; 3methoxy-4-hydroxyphenylglycol, MHPG; and 5-hydroxyindoleacetic acid, 5-HIAA) were measured in 24-h urine collections (low monoamine diet) on the day between the first and second neuro-psychological tests. Acidified samples were frozen until analysis with ion exchange liquid chromatography and fluorescence detection. Volume-adjusted measures were expressed as $\mathrm{ng} / \mathrm{g}$ creatinine per $\mathrm{m} 2$ body area to correct for general somatic metabolic rates and large variations of body size.

Sodium and potassium in urine were analyzed by flame emission spectroscopy with a lithium reference and calcium with atomic absorption spectrophotometry [Beckman, Fullerton, CA (Trudeau and Freier, 1967)]. Using a Hitachi 704 automatic analyzer, inorganic phosphate was determined by ultraviolet detection using the molybdate reaction, and creatinine was measured with the picric acid reaction using modified fixedtime kinetics. The variability between samples ranged as follows: sodium, 3-10\%; potassium, $0-13 \%$, calcium, $1-15 \%$; phosphate, $3-17 \%$; and creatinine, $2-13 \%$. In the patient group, routine blood samples were also analyzed for sodium, potassium, calcium and chloride.

\subsection{Data treatment}

Group comparisons of simple measures (e.g. body weight, creatinine) were made with $t$-tests, but multiple comparisons (e.g. behavior, mono-amines, electrolytes. were made with separate MANOVAs. As the data did not all show a normal distribution, results were checked with the non-parametric MannWhitney $U$-test and all cases where alpha was cited as attaining $5 \%$ or better were confirmed. Pearson-rho correlations were calculated and trend relationships are recorded_0.1 $>P>0.02$., but clear correlations are described as such if they attained the $2 \%$ level of significance or better.

\section{Results}

\subsection{Plasma measures and drinking}

AD patients did not differ from controls on age, weight, gender ratio or education, but did show a lower performance IQ, were poorer in copying complex figures and were significantly more restless (Table 1). Analyses of variance of plasma NPY, catecholamines and drinking behavior showed significant group differences $\left(F_{4,15}=4.2, P=0.018\right.$. that were reflected by $A D$ patients drinking four times as much water as controls and showing nearly twice the levels of NPY of controls (Table 2). Plasma NE and epinephrine levels were non-significantly higher in the study group.

In controls, NPY levels correlated positively with restlessness and the rate of drinking $(r=0.79, \quad P<0.012 ; \quad r=0.75, \quad \mathrm{P}<0.02$., while, unexpectedly, in the $A D$ group, both measures correlated negatively (restlessness: $r=-0.64$, $P<0.036$; drinking: $r=-0.53, P<0.06)$. In $A D$, but not controls, plasma NE levels correlated inversely with overall CPTQ ratings $(r=-0.74$, $P<0.037)$.

In both groups, plasma NE and NPY levels tended to be associated with each other $(r=0.56-0.59,0.09>P>0.06)$, but only in the $A D$ group were plasma epinephrine levels clearly and positively correlated with NPY $(r=0.73$, $P<0.007)$.

\subsection{Urinary electrolytes}

$A D$ and control subjects did not differ in the concentration in urine of creatinine, an indicator of general metabolism (1.12 vs. 1.14 $\mathrm{g} / \mathrm{l} ; t=-0.09, P=0.9)$. However, $A D$ subjects produced less urine $(612 \mathrm{vs} .870 \mathrm{ml} /$ day; $t=-$ 2.2, $P=0.04)$ and thus less creatinine per day (592 vs. $922 \mathrm{mg} /$ day) and less creatinine in relation to their body weight (16.6 vs. 22.8 $\mathrm{mg} / \mathrm{kg}$ per day; $t=-3.3, P=0.004$ ).

A MANOVA for the concentrations of the 4 electrolytes showed a trend for lower calcium levels $(P=0.075)$ that was significant after covarying for creatinine concentration or urinary volume $\left(F_{4,14}=3.3, P=0.043\right.$; one-way 
analysis: $F 1,17=6.1-6.8, P=0.018-0.024$; Fig. $1)$.

However, there were group differ-ences in the urinary production of four electrolytes per kg body wt. $\left(F_{4,15}=6.6, \quad P<0.003\right)$. Daily excretion rates were lower in $A D$ subjects for sodium $\left(F_{1,18}=4.3, P=0.05\right)$, calcium $(F=23.9, P<$ 0.0002 . and phosphate ( $F=5.5, P=0.03$; Fig. 1 ). With creatinine production (or urine volume) as covariate, only the calcium reduction was significant $\left(F_{1,17}=7.7, P=0.01\right)$. Sodium and phosphate levels were not significantly decreased $(P<0.1)$.
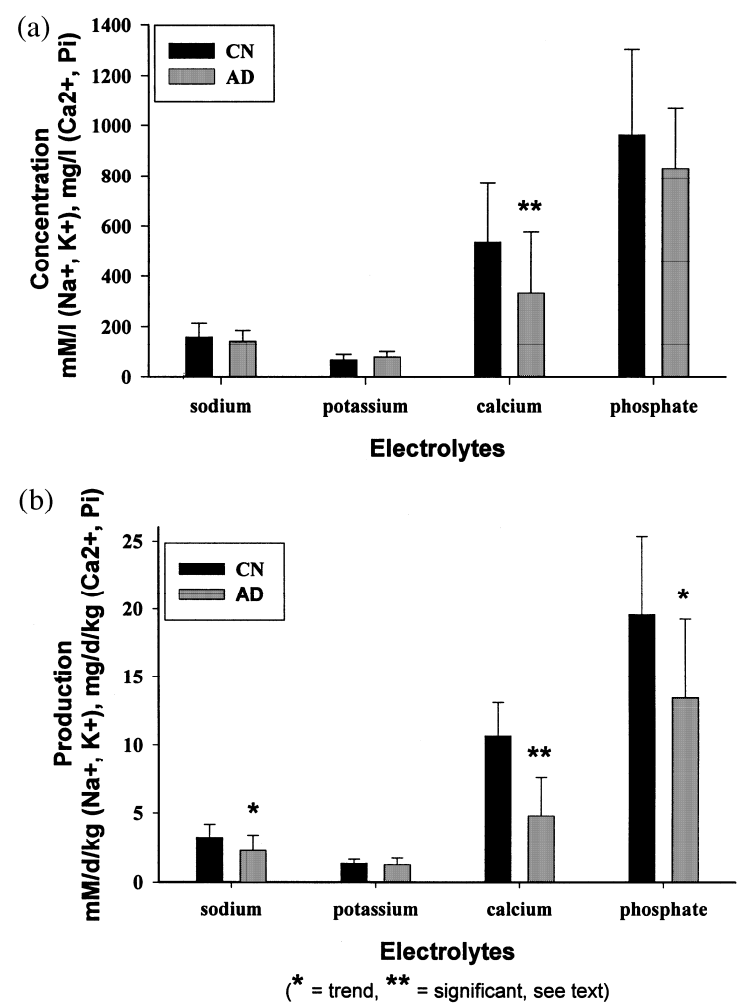

Fig. 1. (a) Electrolyte concentration in urine in control $(\mathrm{CN})$ and ADHD children (AD); and (b) electrolyte production (per $\mathrm{kg}$ per day) in control $(\mathrm{CN})$ and ADHD children (AD).

Urinary Volume and electrolyte measures were not correlated in controls, and calcium and creatinine levels were not correlated with urinary volume in the AD group ( $P=0.4-0.65)$. The excretion of other ions showed variable relationships with urinary volume $\left(\mathrm{Na}^{+}: r=0.43\right.$, $P=0.16 ; \mathrm{K}^{+}: \quad r=0.60, P=0.038 ; \mathrm{P}_{\mathrm{i}}: r=0.66$, $P=0.019$ ).

In both groups NPY levels were inversely but non-significantly related to electrolyte excretion rates: for calcium concentration in the AD group this became significant $(r=-0.61$, $P<0.027)$. Electrolyte measures tended to be negatively related to plasma catecholamine levels $(P=5-10 \%)$ in $A D$ patients, but not in controls.

In control but not AD subjects, drink-ing behavior correlated negatively with calcium excretion $(r=-0.79, P=0.011)$. Drinking did not correlate with the excretion of other electrolytes. In the AD group, increased drinking related weakly to decreases of plasma sodium $(r=-0.54, P<0.055)$. But there were positive correlations for the amount of drinking with the daily volume of urine (=s0.64, $P<0.02$., creatinine $(r=0.6, P<0.05)$, potassium $(r=0.6, \quad P<0.06)$ and phosphate $(r=0.7, P<0.01)$.

\subsection{Urinary monoamines}

In the current small subject sample, measures were consistent with but varied more widely than in the larger group (Oades and Müller, 1997). AD patients showed more 5-HT metabolism (5-HIAA: $U=7, z-2.6, P<0.01$ ) and less NE metabolism, with a build-up of NE levels (NE: $U=12, z=-2.1, P<0.04$; Fig. 2).

In controls urinary catecholamines correlated with plasma NPY levels (e.g. NE: $r=0.76, P=0.04$; DA: $r=0.67, P=0.09$ ) but not with plasma catecholamine levels. Yet drinking was associated with increased monoamine excretion and was negatively correlated with the utilization of each monoamine $\left(\mathrm{NE}_{\mathrm{uti}}\right.$ : $r=-$ $0.8, P=0.02 ; 5-\mathrm{HT}_{\mathrm{util}}: r=-0.7, P=0.07 ; \mathrm{DA}_{\mathrm{util}}: r=-$ $0.75, P=0.04)$. In contrast, in $A D$ patients plasma NPY correlated with no urinary measure, despite plasma NE levels correlating more or less with all urinary catecholamines $(r=0.68-0.87,0.09>P>0.01)$. In contrast to values in controls, no $A D$ urinary monoamine measure correlated with drinking, even though urinary volumes and creatinine were positively related to drinking.

\subsection{Effects of psychostimulant medication}

Five patients received methylphenidate (10-30 mg/day; median, $20 \mathrm{mg} /$ day). A comparison with those not receiving medication with a Student's $t$-test showed no significant differences for plasma measures; 
on medication, NPY measures slightly decreased $(4.36 \pm 2.0$ to $3.78 \pm 1.5 \mathrm{fmol} / \mathrm{ml}, t=-$ $0.55, P=0.59)$ while epinephrine and $\mathrm{NE}$ slightly increased $(96 \pm 92$ to $142 \pm 76 \mathrm{pg} / \mathrm{ml}$, $t=0.87, P=0.41$; and $680 \pm 411$ to $846 \pm 560$, $t=0.59, P=0.57$, respectively).

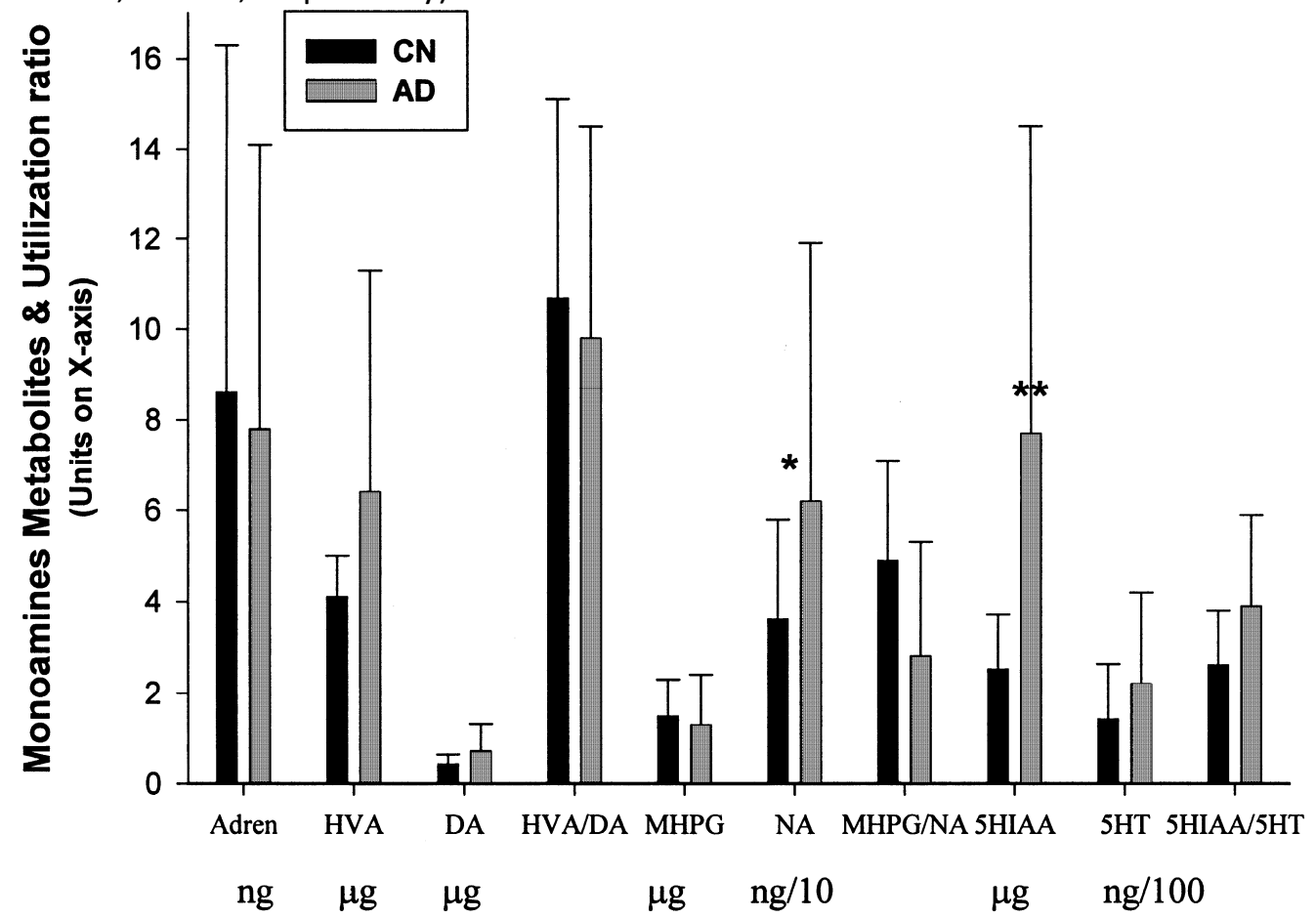

Monoamines, Metabolites $\left(/ \mathrm{mg}\right.$ creatinine $\left./ \mathrm{m}^{2}\right)$ \& Utilization

Fig. 2. Urine (24-h) monoamine activity in healthy control (CN) and ADHD children (AD).

\section{Discussion}

Our initial hypothesis was confirmed by demonstrating that a small sample of ADHD children drank more water and showed higher circulating levels of NPY than their healthy age-matched counter-parts. Unexpectedly, there tended to be inverse relationships in the $A D$ group for drinking and restlessness with NPY levels: in contrast, in controls, (low) levels of drinking and restlessness correlated with (low) levels of NPY.

The increased water intake in $A D$ children could reflect a displacement behavior in that the opportunity to drink was an activity proposed to a particularly receptive subject group. However, as the measures were undertaken on the basis of previous observations, we explore here their potential physiological correlates. Thus, the first question raised is: if NPY is frequently colocalized with catecholamine systems (Dumont et al., 1992), which are themselves implicated in ADHD (dys)function (Oades, 1987), what are the relationships of the monoamines to drinking behavior and NPY levels?

Circulating levels of epinephrine and NE were non-significantly higher in the AD group, and significantly more NE was excreted, as previously reported (Oades, 1987). While some studies report no changes in NE levels, our and their data point to a tendency for decreased utilization (Pliszka et al., 1994; Hanna et al., 1996). Furthermore, we would agree with the arguments of these authors that such increases of NE would likely reflect a mild stress response. For both groups, plasma catecholamines tended to relate positively to NPY levels. However, although urinary catecholamines were related to plasma NPY 
levels in controls, there were no relationships for NPY with urinary amine measures in the $A D$ group. This discontinuity between plasma and urinary measures in patients but not controls is itself indicative of a change of metabolism, an uncoupling of the NPYcatecholamine relationship in ADHD vs. healthy children. This change is consistent with findings from cases of hypertension where increased epinephrine and NE levels reflect sympathetic activity (Fauvel et al., 1992).

A second question is: if physiological mechanisms of thirst frequently reflect changes of electrolyte concentrations, are circulating or excreted levels of electrolytes different in ADHD patients and related to their drinking behavior (or NPY levels)?

Increased drinking in $A D$ patients (not controls) was correlated with an increased volume of water excreted, with decreases of circulating sodium, and with increased excretion of potassium and, particularly, phosphate. Hence, the thirst exhibited may have been genuine and an attempt to counteract a water deficit, for it was noted that $A D$ patients produced less urine (and sodium, calcium and phosphate). These changes could obtain significance for CNS function, considering that manipulations of sodium balance in animals have been reported to influence mesolimbic serotonin and dopamine utilization (Frankmann et al., 1994), transmitters for which anomalous activity is reported for ADHD children (Cook et al., 1995; Castellanos et al., 1996; Oades and Müller, 1997).

The changes recorded are unlikely to be merely an artifact of inadequate urine collection as the differences did not apply to potassium, the monoamines measured in the same sample showed differential changes, and creatinine levels were adequate. The apparent water deficit may have several explanations, including a lack of compliance in one or two individuals despite collection being overseen by staff on the wards. The impact of this was reduced by covariance analysis. Other partial explanations for a water deficit may reflect general metabolic levels, stress and perspiration, subclinical hyperthyroidism and hyper-tension.

A metabolic contribution would seem likely in view of the clearly higher level of physical activity in ADHD children. This contribution may have been heightened due to an interaction with anxiety symptoms recorded in our patients (see methods) and their sensitivity to the stress of a 'test situation'. (We consider it unlikely that drinking rates recorded in the test should be simply extended to give 24-h intake levels, but may reflect autonomic activation). This line of reasoning leads onto a possible contribution of increased thyroid function that would be associated with increased cardiac output, vegetative function, and changes of temperature and perspiration control (West, 1985). There have been several reports of altered thyroid function in samples of ADHD children (Elia et al., 1994; Hauser et al., 1997; Leo et al., 1997). Indeed, we also found increased triiodothyronine levels in a sample of children with conduct disorder and ADHD symptoms (Dmitrieva et al., 1998). The excess NE production in the current study is consistent with this interpretation. Lastly, one could postulate that drinking behavior in $A D$ patients reflects an appetite for specific ions for which there is a metabolic requirement. It is notable that plasma NPY levels had no relationships with electrolyte excretion in controls, but for calcium excretion (production and concentration) there was a negative relationship with NPY levels in the AD group. There is a large literature on the attribution of AD-like symptoms, possibly arising from an allergic response to aspects of the subjects' diet (e.g. Egger et al., 1992; Carter et al., 1993 and references therein). While there may be points of overlap with the present study (e.g. phosphate balance), we are not aware of empirical work that illuminates the present investigation on water balance.

A comparison with five patients on psychostimulant medication for 2-8 weeks showed no signs of changes in levels of NPY with respect to unmedicated patients. Thus there is no indication that methylphenidate normalizes NPY levels. However, it is of interest that levels were not raised, as sub- 
chronic (but not acute) treatment of rats with amphetamine is reported to have increased circulating levels of NPY (Tessel et al., 1985.. The apparent difference in responsivity may be attributable to the predominant effect of methylphenidate on dopamine at the presynaptic uptake site in contrast to a more marked effect of amphetamine on NE, and that at the presynaptic release site (Patrick and Markowitz, 1997).

Our preliminary conclusions are that (a) thirst in ADHD children is related to aspects of their psychopathology (e.g. restlessness, autonomic activity); (b) this thirst relates to general metabolism (decreased creatinine) and sodium homeostasis (less circulating); but (c) the ions most affected by the change of metabolism are calcium and phosphate (decreased rate of excretion). Calcium homeostasis was related to NPY (and catecholamine) metabolism which, according to plasma levels, were likely to be increased in ADHD children. Anomalous control of the water balance in 'hyperactive' children is evident but has received little attention. Studies directed at disentangling potential causes from epiphenomena could advance our understanding of the biological bases of the changed levels of activation characteristic of the ADHD syndrome.

\section{Acknowledgements}

We are grateful to Dr. H. Bussemass and his assistants at the Dr. Eberhard Laboratory, Dortmund for the mono-amine analysis, to Frau Ursula Jacobs for technical help in performing the NPY radioimmunoassay, to Dr. R. Schepker and Professor C. Eggers for their interest and clinical help, and to the referees for their constructive comments.

\section{References}

Aguirre, J.A., Fuxe, K., Hedlund, P., Narvaez, J.A., Cintra, A., Rosen, L., Agnati, L.F., 1992. Neuropeptide $\mathrm{Y} /$ angiotensin II interactions in central cardiovascular regulation of the rat. Brain Research 566, 61-69.

Bald, M., Gerigk, M., Rascher, W., 1997. Elevated plasma concentrations of neuropeptide $Y$ in children and adults with chronic and terminal renal failure. American Journal of Kidney Disorders 30, 23-27.

Carter, C.M., Urbanowicz, M., Hemsley, R., Mantilla, L., Strobel, S., Graham, P.J., Taylore, E., 1993. Effects of a few food diet in attention deficit disorder. Archives of Disease in Childhood 69, 564-568.

Castellanos, F.X., Elia, J., Kruesi, M.J.P., Marsh, W.L., Gulotta, C.S., Potter, W.Z., Ritchie, G.F., Hamburger, S.D., Rapoport, J.L., 1996. Cerebrospinal fluid homovanillic acid predicts behavioral response to stimulants in 45 boys with attention deficit/hyperactivity disorder. Neuropsychopharmacology 14, 125-137.

Cook, E.H., Stein, M.A., Ellison, T., Unis, A.S., Leventhal, B.L., 1995. Attention deficit hyperactivity disorder and whole-blood serotonin levels: effects of comorbidity. Psychiatry Research 57, 13-20.

Dmitrieva, T.N., Oades, R.D., Hauffa, B.P., Eggers, C., 1998. Dehydroepiandrosterone sulfate (DHEA-S) levels are high in young patients with conduct disorder (submitted).

Dumont, Y., Martel, J.C., Fornier, A., St-Pierre, S., Quirion, R., 1992. Neuropeptide $Y$ and neuropeptide $Y$ receptor sub-types in brain and peripheral tissues. Progress in Neurobiology 38, 125-167.

Egger, J., Stolla, A., McEwen, L.M., 1992. Controlled trial of hyposensitisation in children with food induced hyperkinetic syndrome. Lancet 339, 1150-1153.

Elia, J., Gulotta, C., Rose, S.R., Marin, G., Rapoport, J.L., 1994. Thyroid function and attention-deficit hyperactivity disorder. Journal of the American Academy of Child and Adolescent Psychiatry 33, 169-172.

Erlinge, D., Ekman, R., Thulin, T., Edvinsson, L., 1992. Neuropeptide Y-like immunoreactivity and hypertension. Journal of Hypertension 10, 1221-1225.

Fauvel, J.P., Bernard, N., Hadj-Aissa, A., Laville, M., Labeeuw, M., Cuisinard, G., Pozet, N., Sassard, J., Zech, P., 1992. Urinary catecholamines and methoxy-amines during psychological stress in subjects with different genetic risk of hypertension. Biogenic Amines 8, 161-166.

Fontes, M.A.P., Silva, L.C.S., Campagnole-Santos, M.J., Khosla, M.C., Guertzenstein, P.G., Santos, R.A.S., 1994. Evidence that angiotensin (1-7) plays a role in the central control of blood pressure at the ventrolateral medulla acting 
through specific receptors. Brain Research 665, 175-181.

Frankmann, S.P., Broder, L., Dokko, J.H., Smith, G.P., 1994. Differential changes in central monoaminergic metabolism during first and multiple sodium depletions in rats. Pharmacology, Biochemistry and Behaviour 47, 617-624.

Fregly, M.J., Rowland, N.E., 1995. Effect of administration of angiotensin $\|$ and isoproterenol, alone and in combination, on drinking and tail skin temperature of the rat. Pharmacology, Biochemistry and Behaviour 51, 83-88.

Guyton, A.C., Hall, J.E., Lohmeier, T.E., Kastner, P.R., 1981. Blood pressure regulation: basic concepts. Federation Proceedings 40, 22522256.

Hanna, G.L., Ornitz, E.M., Hariharan, M., 1996. Urinary epinephrine excretion during intelligence testing in attention- deficit hyperactivity disorder and normal boys. Biological Psychiatry 40, 553-555.

Hauser, P., Soler, R., Brucker-Davis, F., Weintraub, B.D., 1997. Thyroid hormones correlate with symptoms of hyperactivity but not inattention in attention-deficit hyperactivity disorder. Psychoneuroendocrinology 22, 107-114.

Leo, R.J., Batterman-Faunce, J.M., Pick-hardt, D., Cartagena, M., Cohen, G., 1997. Utility of thyroid function screening in adolescent psychiatric inpatients. Journal of the American Academy of Child and Adolescent Psychiatry $36,103-111$.

Lettgren, B., Wagner, S., Hänze, J., Lang, R.E., Rascher, W., 1992. Elevated plasma concentrations of neuropeptide $Y$ in adolescents with primary hypertension. Journal of Human Hypertension 8, 345-349.

Oades, R.D., 1987. Attention deficit disorder with hyperactivity (ADDH): contribution of catecholaminergic activ-ity. Progress in Neurobiology 29, 365-391.

Oades, R.D., 1989. Attention deficit disorder and hyperkinetic syndrome: biological perspectives. In: Sagvolden, T., Archer, T. (Eds.), Attention Deficit Disorder: Clinical and Basic Research. Lawrence Erlbaum Associates, Hillsdale, NJ, pp. 353-368.

Oades, R.D., Müller, B., 1997. The development of conditioned blocking and monoamine metabolism in children with attention-deficithyperactivity disorder or complex tics and healthy controls: an exploratory analysis. Behavioral Brain Research 88, 95-102.

Oades, R.D., Röpcke, B., Eggers, C., 1994. Monoamine activity reflected in urine of young patients with obsessive compulsive disorder, psychosis with and without reality distortion and healthy subjects: an explorative analysis. Journal of Neural Transmission 96, 143-159.

Oades, R.D., Röpcke, B., Schepker, R., 1996a. A test of conditioned blocking and its development in childhood and adolescence: relationship to personality and monoamine metabolism. Developmental Neuropsychology 12, 207-230.

Oades, R.D., Dittmann-Balcar, A., Schepker, R., Eggers, C., Zerbin, D., 1996b. Auditory eventrelated potentials (ERPs) and mismatch negativity ( $\mathrm{MMN})$ in healthy children and those with attention-deficit or Tourette/tic symptoms. Biological Psychology 43, 163-185.

Patrick, P.S., Markowitz, J.S., 1997. Pharmacology of methylphenidate, amphetamine enantiomers and pemoline in attention-deficit hyperactivity disorder. Human Psychopharmacology 12, 527-546.

Pliszka, S.R., Maas, J.W., Javors, M.A., Rogeness, G.A., Baker, J., 1994. Urinary catecholamines in attention-deficit hyperactivity disorder with and without comorbid anxiety. Journal of the American Academy of Child and Adolescent Psychiatry 33, 1165-1173.

Pruszczyk, P., Chlebus, M., 1995. Plasma neuropeptide $Y$ during dynamic exercise in patients with essential hypertension. Clinical and Experimental Hypertension 17, 769-785.

Rascher, W., Kremens, B., Wagner, S., Feth, F., Hunneman, D.H., Lang, R.E., 1993. Serial measurements of neuropeptide $Y$ in plasma for monitoring neuroblastoma in children. Journal of Pediatrics 122, 914-916.

Sagvolden, T., Archer, T., 1989. Attention Deficit Disorder: Clinical and Basic Research. Lawrence Erlbaum Associates, Hillsdale, NJ.

Sagvolden, T., Pettersen, M.B., Larsen, M.C., 1993. Spontaneously hypertensive rats (SHR) as a putative animal model of childhood hyperkinesis: SHR behavior compared to four other strains. Physiology and Behaviour 54, 1047-1055.

Sato, K., Crofton, J.T., Wang, Y., Share, L., 1995. Effects of gender on the central actions of neuropeptide $Y$ and norepinephrine on 
vasopressin and blood pressure in the rat. Brain Research 689, 71-78.

Schmidt, R., Fazekas, F., Offenbacher, H., Lytwyn, H., Blematl, B., Niederkorn, A., Horner, S., Payer, F., Freidl, W., 1991. Magnetic resonance imaging white matter lesions and cognitive impairment in hypertensive individuals. Archives of Neurology 48, 417420.

Tessel, R.E., DiMaggio, D.A., O'Donohue, T.L., 1985. Amphetamine-induced changes in immunoreactive NPY in rat brain, pineal gland and plasma. Peptides 6, 1219-1224.

Trudeau, D.L., Freier, E.F., 1967. Determination of calcium in urine and serum by atomic absorption spectrophotometry (AAS). Clinical Chemistry 13, 101-114.

West, J.B. (Eds.), 1985. Best and Taylor's Physiological Basis of Medical Practice, 11th ed. Williams and Wilkins, London, p. 879.

Xu, Z.C., Herbert, J., 1994. Regional suppression by water intake of c-fos expression induced by intraventricular infusions of angiotensin II. Brain Research 659, 157-169. 